\title{
Vesical calculi in El Obeid Hospital, Western Sudan. El Bushra Ahmed Doumi
}

\begin{abstract}
:
Objectives: To study the pattern and demographic features of patients with urinary bladder calculi, in El Obeid Hospital; Western Sudan.

Patients and Methods: In this study the recordsof sixty patients with urinary bladder stones were reviewed. The data were analyzed for age, sex, locality, clinical features, the treatment offered and outcomes.

Results: The male: female ratio was $14: 1$. 53 patients $(88.3 \%)$ were children, below 10 years.

The majority were from distant rural areas with features of malnutrition and anaemia. 7 patients $(11.7 \%)$ were adults with urinary outlet obstruction.

Conclusions: Urinary bladder calculi were prevalent in children from rural areas with features of malnutrition, where as such calculi were not uncommonly found in adults from the same background secondary to urinary outlet obstruction.
\end{abstract}

Key words: Urinary bladder stones, Western Sudan.

$\mathrm{T}$ The presence of stones in the urinary tract is known since antiquity ${ }^{1,2}$. It is quoted that the incidence varies from $2 \%$ to $5 \%$, that probably one in twenty of the adult population will develop urinary calculi at some time of their life ${ }^{2,4}$. Several climatic, environmental, genetic, septic and dietary factors had been incriminated in the aetiology of stones formation ${ }^{3-6}$. The roles of these factors differ as the age of the affected person advances.

Two hundred and fifty years ago vesical calculi were very common in England, but a latter survey has shown that the disease had gradually disappeared ${ }^{3}$. However, the condition is still reported from different regions of the developing world ${ }^{6-14}$; where its prevalence is linked to the hot climate, poverty and deficiency in animal protein intake.In Sudan, urolithiasis is a common disease $^{5-12}$. In this study we document the prevalence of vesical stones among the patients reporting to our hospital which serves a wide community in the sub-saharan zone of Western Sudan where drought, desertation, displacement and conflicts had swept the society for more than two decades.

\footnotetext{
Consultant General Surgeon,

Associate Professor,

The University Surgical Unit,

El Obeid Teaching Hospital,

El Obeid- Sudan.

e.mail: elbushradoumi@hotmail.com
}

\section{Patients and method:}

This is a prospective descriptive study. All patients who were admitted to the wards of the University Surgical Unit, in El Obeid Teaching Hospital with the diagnosis of vesical stone over 4 years period (1997 to 2000) were included. The data were collected by separate discharge sheets in which the information regarding the patients was recorded. The main characteristics included age, gender, locality, clinical presentations and general nutritional status of the patient. Investigations regarding the blood chemistry and stone composition were not performed for the majority of the patients and hence that information was excluded. The data analysis was done manually.

\section{Results:}

There were 60 patients 56 of them were males $(93.3 \%)$, giving a male: female ratio of $14: 1$. $18.3 \%$ of the patients were among displaced families at the peripheries of the town, whereas $81.7 \%$ were from distant rural areas. The age distribution was shown in table 1, indicating that 53 patients $(88.3 \%)$ were children.

The predominance of males in this study compared to the findings of other authors is shown in table 2. Vesical stones with different size and shapes were encountered [Fig 1\&2] 
Table 1: Age distribution, $n=60$.

\begin{tabular}{c|cc} 
Age in years & $\mathrm{N}$ & $\%$ \\
\hline $01-10$ & 49 & 81.7 \\
$11-20$ & 04 & 06.7 \\
$21-30$ & 00 & 00 \\
$31-40$ & 00 & 00 \\
$41-50$ & 00 & 00 \\
$51-60$ & 01 & 01.6 \\
$>60$ & 06 & 10.0 \\
\hline Total & 60 & 100.0
\end{tabular}

Table 2: Male predominance as reported in different series.

\begin{tabular}{l|clcc} 
Author & Year & Country & $\mathrm{N}$ & $\%$ \\
\hline Thalut $^{13}$ & 1976 & Indonesia & 87 & 92 \\
ElGohary $^{5}$ & 1982 & Kuwait & 34 & 91 \\
Sayasone $^{14}$ & 2004 & Lao & 40 & 77.5 \\
Sharma $^{15}$ & 2004 & Nepal & 43 & 97 \\
Doumi* $^{*}$ & 2008 & Sudan & 60 & 93
\end{tabular}

* The present study.

Clinical presentations: 48 patients $(80 \%)$, presented with sharp pain and dysuria felt at the initiation of micturition radiating to the tip of the penis or vulva. 12 patients $(20 \%)$ who were all males, presented with acute retention of urine. 50 patients $(83.3 \%)$ who were all children i.e. $92.6 \%$ of the children among the study group, had signs of malnutrition and anaemia (haemoglobin content lower than 10 $\mathrm{g} / \mathrm{dl})$. 56 patients $(93.3 \%)$ were of low socioeconomic status and 4 patients $(6.7 \%)$ were of moderate status. $20 \%$ of the patients reported for regular follow up extending from two to six months.

Fig 1: large solitary stone

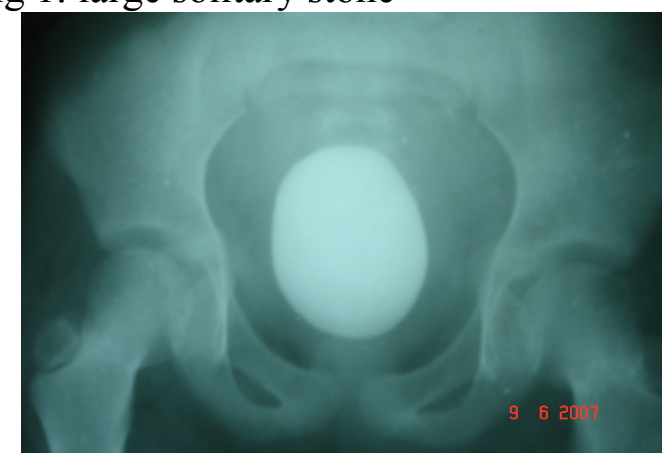

\section{Discussion:}

The oldest urinary bladder stone discovered dates back to $4800 \mathrm{BC}$, and was found by archeologists in Egypt $^{1}$. During the $19^{\text {th }}$ century and the beginning of the $20^{\text {th }}$ century prevalence of vesical stones was reported from Europe, Japan and the United States, but the disease was described to be disappearing in children there, during recent decades ${ }^{2-4}$. Similar pattern was reported from rich countries in the region like Kuwait, Saudi Arabia and Tunisia ${ }^{5-8}$.

Fig2: multiple large stones

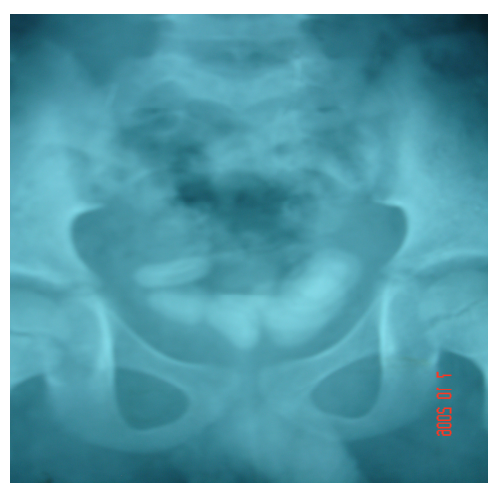

In this study, out of the 60 patients analyzed; 53 patients $(88.3 \%)$ were children of whom 49 were below 10 years of age. The remaining 4 children their ages ranged between 10.5 and 12 years. History of frequent episodes of diarrhoea was admitted by all parents, of which more than 3 attacks during previous year was noted in $65 \%$ of the patients. Most of the patients were from rural locality $(81.7 \%)$ belonging to poor families with low socioeconomic status (93.3\%). That was confirmed by the finding that $76 \%$ of the children studied showed clinical signs of malnutrition, whereas $86 \%$ had a haemoglobin content of less than $10 \mathrm{~g} / \mathrm{dl}$. The association between under nutrition and endemic vesical calculi was documented before $^{9-13}$.

The majority of the patients were males (93.3\%). Predominance of endemic vesical stones in male children was also reported ${ }^{14-16}$. The comparison of the findings of different authors shown in table 2 indicated that in 4 of those series males were 91, 92, 93 and 97 per cent of the study group. 
The commonest presenting symptom in children with endemic vesical stones was sharp agonizing pain felt at the start of micturition in the suprapubic area and radiates to the genitalia. It is our observation that, the male child was commonly frightened of pain and withholds micturition scratching the tip of his penis, but the pain soon subsides after micturition ends and the child returns back to play peacefully until the beginning of another act of micturition. There were no constitutional symptoms like fever, lassitude or malaise. 12 children (20\%) reported with acute retention of urine due to stone impacted at the bladder neck or urethra. Sayasone et al reported acute urinary retention in $32 \%$ of their series in $\mathrm{LaO}^{15}$. Although urinary Bilharziasis is not uncommon in the south and south west parts of this region, but we could find no association between its prevalence and vesical stones formation in the study group. Similar observation was made before $^{17}$.

The diagnosis was established by plain X-rays of the urinary bladder or ultra-sound scan. All patients were treated surgically with open suprapubic cystolithotomy. The procedure was $1^{\text {st }}$ introduced by Pierre Franco in $1500 \mathrm{~s}^{1}$. Although, Hippocrates more than 23 centuries ago warned that: "to cut through the bladder is lethal", we found the procedure was simple, easy, safe, catheter less, drain less and without noticeable complications ${ }^{18}$. This indicates that such patients can be successfully treated in distant rural hospitals where the disease is prevailing, by junior doctors using available anaesthetics like ketamine or halothane masks.

Seven patients $(11.7 \%)$ of the study group were elderly males, their ages ranged from 55 to 80 years. In those patients the vesical calculi were found to be secondary to bladder outlet obstruction produced by benign prostatic hyperplasia, similar to the previous reports in different series ${ }^{19-21}$. All patients were offered open transvesical prostatectomy with open cystolithotomy; with non eventful outcomes.
Only $20 \%$ reported for regular follow up for limited periods varying from two to six months. Although no recurrence was noted among the patients, yet no solid conclusions could be made within such a short time.

\section{References:}

1. Haddad FS. Highlights on the History of Medicine in the Middle East. T Klin J Med Ethics, Law and History 2002; 10: 243-57.

2. Qaader DS, Yousif SY, Mahdi LK. Prevalence and etiology of urinary stones in hospitalized patients in Baghdad. Eastern Mediterranean Health Journal 2006; 12(6): 853-61.

3. Lynn E. Recent advances in the management of urinary tract calculi. Postgraduate Doctor-Middle East. 1986; 9(8): 492-502.

4. James G. Bladder calculi. Postgraduate DoctorMiddle East 1978; 1(2): 42-48.

5. El Gohary MA, Cook RC. Vesical stones in children in Kuwait. Prog Pediatr Surg 1982; 15: 243-54.

6. Al-Rasheed SA, el-Faqih SR, Husain I, et al. The aetiological and clinical pattern of childhood urolithiasis in Saudi Arabia. Int Urol Nephrol 1995; 27(4): 349-55.

7. Refeidi A. Vesical Stones in Asir Region. Saudi Med J 1996; 17(2): 158-61.

8. Kamoun A, Daudon M, Kabaar N, et al. Etiologic factors of urinary lithiasis in Tunisian children. Prog Urol 1995; 5(6): 942-45.

9. Ibrahim A, Zain M, Beleil O. Clinical aspects of urolithiasis in the Sudan. J R Coll Surg Edinb 1979; 24(1): 34-37.

10. Ibrahim A, Zain M, Beleil O. Hyperuricaemia in Sudanese urinary stone formers. Sud Med J 1977; 15(4): 57-60.

11. Kambal A, Wahab SM, Khatab AH. The pattern of urolithiasis in the Sudan. Br J Urol 1978; 50(6): 376-77.

12. Hussain F. Urolithiasis in North East Bombay. Int. Urol. Nephrol 1990; 22: 119-24.

13. Johnson O. Vesical calculus in Ethiopian children. Ethiop Med J 1995; 33(1): 31-35.

14. Thalut K, Rizal A, Brockis JG, et al. The endemic bladder stones of Indonesia: epidemiology and clinical features. Br J Urol 1976; 48(7): 617-21.

15. Sayasone $S$, Odermatt $P$, Khammanivong $K$, et al. Bladder stones in childhood: a descriptive study in a rural setting in Saravan Province, Lao PDR. Southeast Asian J Trop Med Public Health 2004; 35(suppl 2): 50-52.

16. Sharma N, Furber A, Lemaster J. Study on urinary bladder stone cases at Okhaldhunga Hospital, Nepal. 1988-1994. Nepal Med Coll J 2004; 6(1): 49-52. 
17. Ibrahim A. The relationship between urinary Bilharziasis and urolithiasis in the Sudan. $\mathrm{Br} \mathrm{J}$ Urol. 1978; 50(5): 294-7.

18. Rattan KN, Bhatia V, Ratan SK, et al. Catheterless and drainless open suprapubic cystolithotomy in children: a safe procedure. Pediatr Surg Int 2006; 22(3): 255-8.
19. Abdalla BA, Ahmed SAM, Khattab AH, et al. Recurrent urinary tract stones in Sudanese patients. Sud Med J 1996; 34(2): 36-38.

20. Schwartz BF, Stoller ML. The vesical calculus. Urol Clin North Am 2000; 27(2): 333-46.

21. Douenias R, Rich M, Badlani G, et al. Predisposing factors in bladder calculi. Review of 100 cases. Urology 1991; 37(3): 240-43. 